Original Research Article

\title{
Biosimilar etanercept: a real world safety and patient related outcomes from a single centre
}

\author{
Prasan Deep Rath ${ }^{1}$, Swetal Chandraprakash Pandey ${ }^{2 *}$
}

Department of Rheumatology, ${ }^{1} \mathrm{HOD},{ }^{2}$ Fellow, Max

Superspeciality Hospital, Saket, New Delhi, India

Received: 24 January 2019

Revised: 28 February 2019

Accepted: 14 March 2019

*Correspondence to:

Dr. Swetal Chandraprakash

Pandey,

Email: Swetal.pandey@

yahoo.com

Copyright: (C) the author(s), publisher and licensee Medip Academy. This is an openaccess article distributed under the terms of the Creative Commons Attribution NonCommercial License, which permits unrestricted noncommercial use, distribution, and reproduction in any medium, provided the original work is properly cited.

\begin{abstract}
Background: Biosimilars are expected to provide affordable and quality treatment equivalent to the biologics in various rheumatic disorders. Presently, the data available on the safety and effectiveness of biosimilars is very scarce. The objective of the present study was to assess the safety profile of intended biosimilar of etanercept developed by Intas pharmaceuticals Ltd. (Intacept) in Rheumatoid arthritis (RA), spondyloarthropathy (SpA), ankylosing Spondylitis (AS), juvenile idiopathic arthritis (JIA) and psoriatic arthritis (PsA).

Methods: In single center, retrospective observational study, all patients were enrolled in routine clinical practice who received Intended biosimilar of Etanercept (Intacept) and the following data was collected. Basic demographic profile, disease and duration of therapy, any adverse event, patient's global assessment of disease activity on visual analogue scale (0 to 100), patient's overall experience with Intended biosimilar etanercept (Intacept).
\end{abstract}

Results: Total 70 patients were enrolled (41males and 29 females) having RA (42), AS (11), SpA (13), JIA (2) AND PsA (2). The mean duration of follow up was $8 \pm 1.7$ months. $10 \%$ patients reported adverse events like injection site pain $(4.29 \%)$, fever $(2.86 \%)$, redness $(1.42 \%)$ and weight gain $(1.42 \%) .45 \%$ patients had LTBI screen positive and were initiated on chemoprophylaxis with Rifampicin and INH 4weeks prior to Intacept. About $24 \%$ of patients dropped due to various reasons like affordability issue $(5.7 \%)$, inadequate response $(8.6 \%)$, no response $(10 \%)$ and side effects $(5.7 \%) .51 .4 \%$ patients observed more than $50 \%$ improvement in global disease activity with Intacept while $10 \%$ patients did not get any response with the treatment. $77.2 \%$ patients perceived the overall therapy with Intacept as excellent, very good, good or OK while $22.8 \%$ patients rated Intacept therapy as non-satisfactory.

Conclusions: The study leads to the conclusion that Intended biosimilar of etanercept (Intacept) was safe and well tolerated in various rheumatic disorders in a real-world scenario.

Keywords: Biosimilar safety, Intended biosimilar Intacept

\section{INTRODUCTION}

Biologic drugs like TNF inhibitors have revolutionized the management of Rheumatoid arthritis and spondyloarthropathy leading to early and prompt control over disease activity. TNF which is naturally occurring cytokine ,has a central role in pathogenesis of rheumatoid arthritis , psoriatic arthritis. Etanercept is a soluble, dimeric, fusion protein which consist of extracellular ligand binding protein (two copies) of the human tumour necrosis factor (TNF) p75 receptor which is linked to the constant $(\mathrm{Fc})$ portion of human immunoglobulin G1. But, the major drawback with biologics is their cost.

The United States Food and Drug Administration (FDA) defines a biosimilar as "a biological product that is highly similar to and has no clinically meaningful differences from an existing FDA - approved reference product."”

The evolution of biosimilars has addressed this issue very promptly by providing affordable and quality treatment equivalent to the innovator biologics (reference medicinal 
products). Biosimilars which are developing drug class ,designed to use interchangeably with biologics.They are typically large, complex proteins . Biosimilars have to be identical in terms of immunogenicity, efficacy and side effects to their reference biologics.

The manufacturing process involves production within living cells, they undergo fewer clinical trials than reference biologics which ultimately reduces production cost as compared to reference biologic. The synthesis pathway of the reference biologic is proprietary. Biosimilar developers analyse final biologic and then attempt to reverse engineer a pathway. ${ }^{3}$

Not much data is available on the effectiveness and safety of these biosimilars. This study aims to evaluate the safety and patient perceived effectiveness of one of the intended Biosimilar of Etanercept developed by Intas Pharmaceuticals Ltd. (Intacept).

\section{Objective}

- To assess the safety profile of intended biosimilar etanercept developed by Intas pharmaceuticals Ltd (Intacept).

- To assess patient related outcome of Intacept in rheumatoid arthritis (RA), spondyloarthropathy (SpA), ankylosing Spondylitis (AS), juvenile idiopathic arthritis (JIA) and psoriatic arthritis (PsA).

\section{METHODS}

A single centered, retrospective observational study for a period of 8 months (February 2018-september 2018) on patients who were enrolled in our" Arthritis pain and Rheumatology clinic", receiving the intended biosimilar Intacept fulfilling the following criteria.

\section{Inclusion criteria}

- $\quad$ Patients with axial and/or peripheral SpA (according to ASAS criteria)

- Patient with Rheumatoid arthritis diagnosed as per ACR/EULAR 2010 criteria

- Patient with psoriatic arthritis diagnosed as per CASPER criteria

- Those with active disease (>3.5 ASDAS CRP) despite a 1-month trial of at least two NSAIDs (for axial symptoms only) with or without 3-month trial of DMARDs (for peripheral joint symptoms), in patients with rheumatoid arthritis DAS $28 \mathrm{CRP}>5.1 .^{4,5}$

\section{Exclusion criteria}

- Patients who did not complete at least 12 weeks of etanercept biosimilar therapy or

- Patients with active tuberculosis, current or past history of hepatitis $\mathrm{B}$, hepatitis $\mathrm{C}$ or human immunodeficiency virus, demyelinating disease, alcohol abuse, psychiatric illness, congestive heart failure, history of any form of cancer within the past 10 years, history of serious infection requiring hospitalization in the past 6 months, and history of any surgery in the past 12 weeks.

Screening for latent tuberculosis (TB) included chest Xray, interferon gamma release assay ("Quantiferon-TBGold"), and Mantoux test (1 TU).

In addition, hepatitis B surface antigen and anti-hepatitis $\mathrm{C}$ virus status were also obtained before starting anti-TNF therapy. Patients with latent TB received were treated appropriately before starting intended biosimilar Intacept .

Patients who were prescribed Intacept 25 or $50 \mathrm{mg}$ subcutaneously once weekly were enrolled for the study and were followed up to assess its the safety and patient perception regarding its effectiveness. Some were shifted from original molecule Etanercept due to financial issues. Proper counselling was done before the shift. The patients were instructed to report to the clinic in case of occurrence of any adverse event.

On the follow up visit, patients were clinically assessed to check for remission and patient's global assessment of disease activity was measured on visual analogue scale $(0$ to 100). Patients overall experience with Intacept was also assessed as excellent, very good, good, OK or nonsatisfactory. Patients were also advised physiotherapy in the form of spinal extension exercises, deep breathing exercises, and regular aerobic exercises such as brisk walk, cycling, and swimming.

The number of patients achieving remission or dropping out of the study was also noted with reason for drop out. During the study, the patients were not subjected to any of the investigations which otherwise would not have been done in routine clinical practice.

\section{RESULTS}

Total 70 patients, 41 males and 29 females were enrolled in the study. The mean age of patients was $42.35 \pm 15.7$ years. 2 patients of JIA were of age less than 16 years.

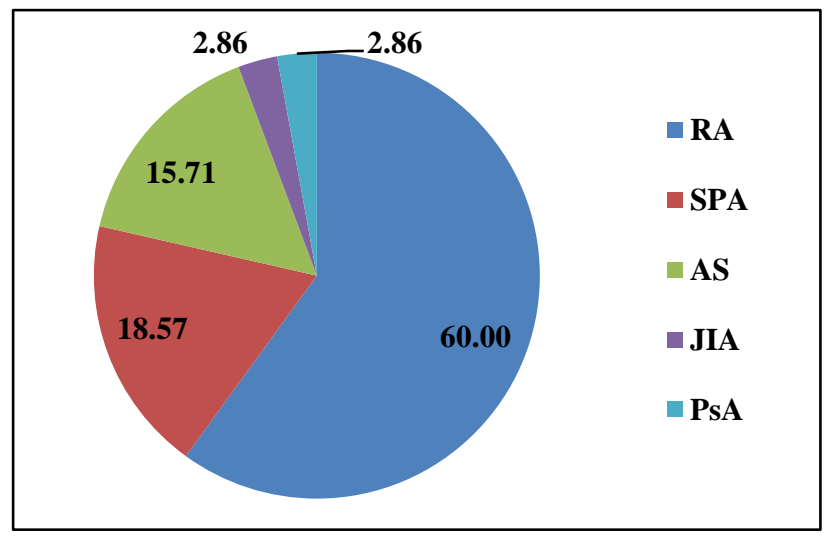

Figure 1: Disease wise distribution of patients. 
The study group included 42 patients of rheumatoid arthritis with female preponderance $(59.5 \%)$ while all 11 AS patients were males. SpA also had male preponderance (11 males out of 13 patients). JIA and PsA contributed 2 patients each to the total patient pool (Figure 1).

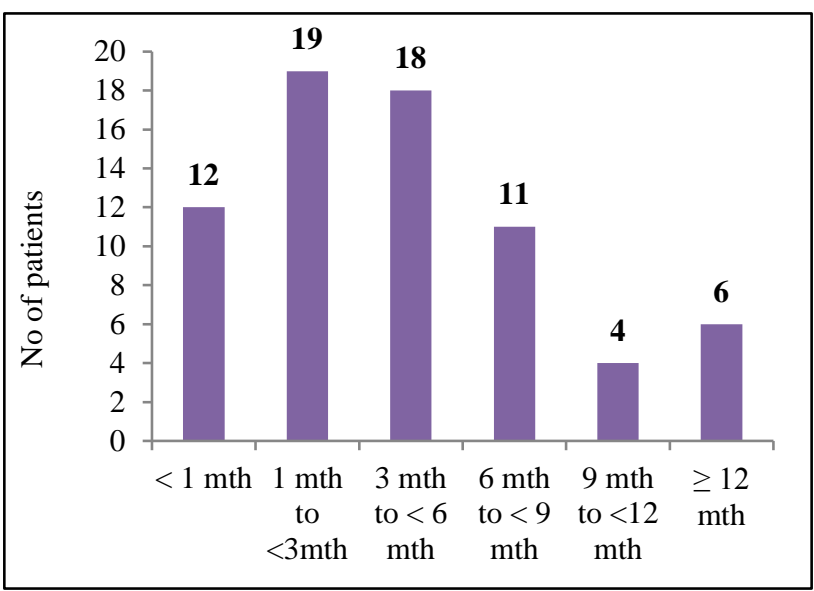

Figure 2: Duration of therapy wise distribution of cases.

Total 61 patients were prescribed $50 \mathrm{mg}$ of Intacept while 8 patients were prescribed $25 \mathrm{mg}$ of Intacept twice in a week through $\mathrm{SC}$ route.

One patient shifted from $25 \mathrm{mg}$ twice weekly to $50 \mathrm{mg}$ once weekly dose. The mean duration of follow up of the patients was $8.01 \pm 1.7$ months. $55.7 \%(\mathrm{n}=39)$ of the patients remained on therapy for a duration of 3 months or more (Figure 2).

\section{Safety analysis}

The therapy was well tolerated in most patients with $90 \%$ of patients not reporting any side effect (Table 1). The side effects reported in the study were injection site pain, fever, redness and weight gain. One patient ( $79 \mathrm{yrs}$ ) died within 2 weeks of starting Intacept due to cause unrelated to therapy.

Table 1: Adverse events.

\begin{tabular}{|ll|}
\hline Adverse event & \% of patients (n) \\
\hline Injection site pain & $4.29 \%(3)$ \\
\hline Fever & $2.86 \%(2)$ \\
\hline Redness & $1.42 \%(1)$ \\
\hline Weight gain & $1.42 \%(1)$ \\
\hline
\end{tabular}

About $24 \%$ of patients dropped of the study due to various reasons (Figure 3). Common reasons for dropping out were affordability issue $(5.7 \%)$, inadequate response $(8.6 \%)$, no response $(10 \%)$ and side effects $(5.7 \%)$.

Two patients stopped taking Intacept due to second opinion from some other rheumatologist. Two patients discontinued the treatment as they achieved remission.

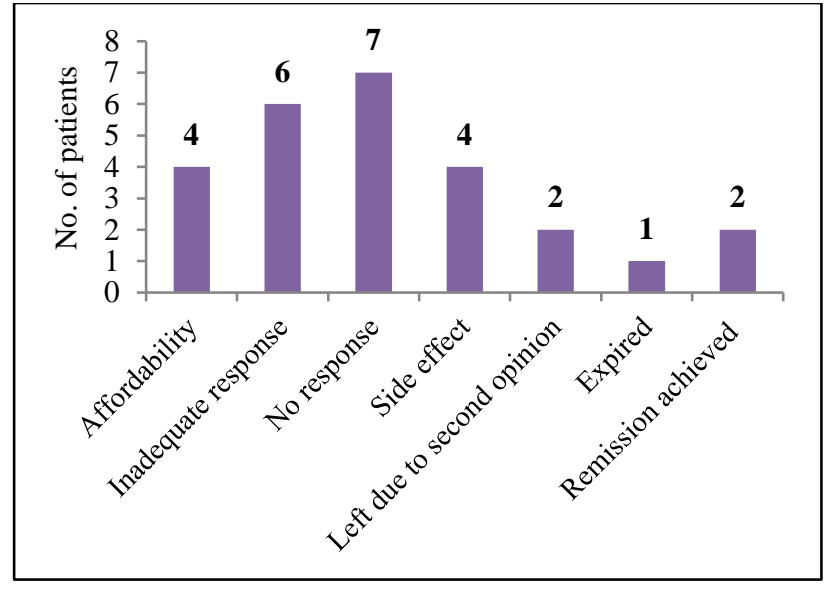

Figure 3: Cause wise distribution of dropout cases.

\section{Patient perception of drug effectiveness}

On clinical assessment, total 6 patients $(8.57 \%)$ achieved remission within a mean duration of $4.16 \pm 3.9$ months. Improvement in global disease activity was noted in visual analogue scale $(0-100)$. $51.4 \%$ patients observed more than $50 \%$ improvement in global disease activity with Intacept while $10 \%$ patients did not get any response with the treatment (Figure 4).

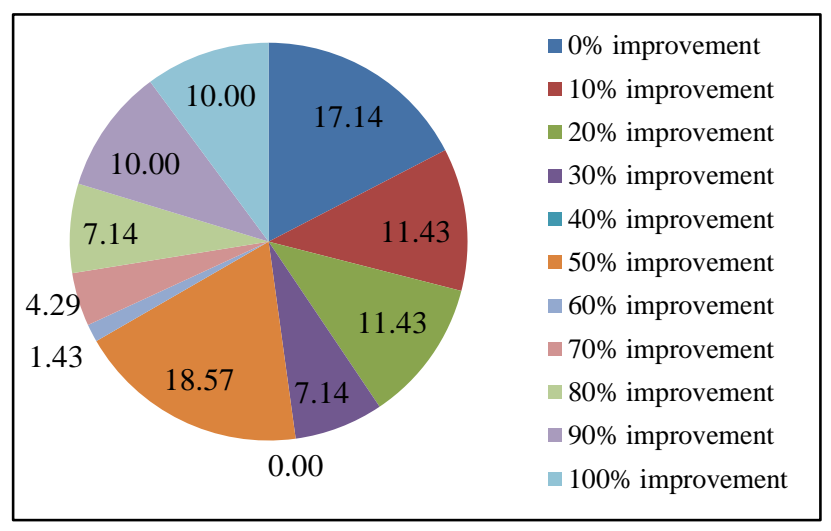

Figure 4: Patient distribution as per improvement in global disease activity (Visual Analogue Scale).

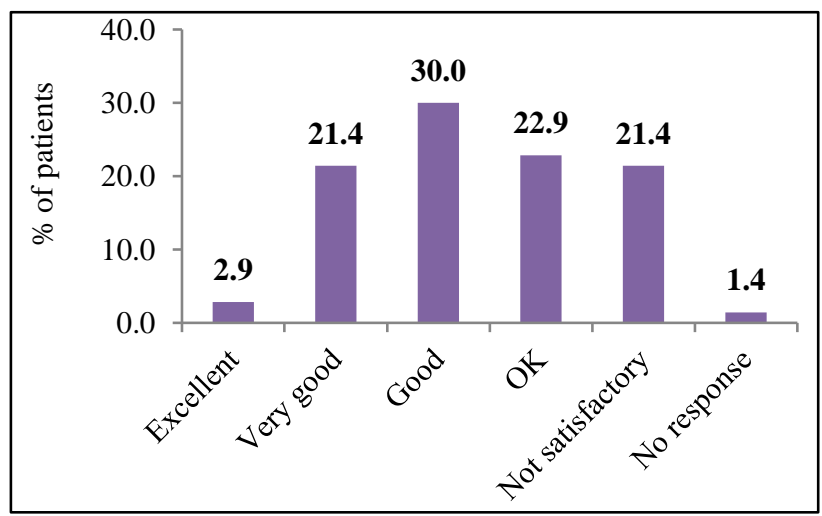

Figure 5: Patient's assessment of overall experience with Intacept. 
About $77.2 \%$ patients perceived the overall therapy with Intacept as excellent, very good, good or OK while $22.8 \%$ patients rated Intacept therapy as non-satisfactory (Figure $5)$.

\section{DISCUSSION}

Etanercept has been established as an effective and safe TNF inhibitor in various immunological disorders like RA, AS, JIA and PsA. Most of the published data on etanercept specifically refers to the innovator. In current era, the concept of biosimilars is rapidly being taken up because of their promising effectiveness and safety profile. Unfortunately, the data on biosimilars is scarce and hence, this study was taken up to evaluate the real time in clinic safety and patient perceived effectiveness of one of the etanercept intended biosimilar developed and marketed by Intas Pharmaceuticals Ltd., under the brand name of Intacept.

The sex distribution of RA, AS and SpA patients in this study were in line with the common epidemiology of respective disorders though proportion of female patients was not as high in RA as expected. ${ }^{6,7}$

The major concerns regarding biosimilars are adverse effects, efficacy and immunogenicity when switching from a biologic to a biosimilar, and long-term effects. ${ }^{8}$ Two recent trials conducted in 2017, which compared the implications of switching from an infliximab innovator to biosimilar, in IBD patients. Results showed enhanced clinical effectiveness and a similar side effect profile. ${ }^{9,10}$ In terms of switching between biologic and biosimilar. No increased risk of adverse events was noted in studies in which switching between two structurally different proteins with similar intended effect was done. ${ }^{11}$ The concern that has yet to be addressed is the potential longterm effects.

A similar Indian study by Ashok Kumar et al , with two etanercept biosimilar comparison in SpA Indian patients. ${ }^{12}$ Present study reports $21.4 \%$ patients rating Intacept therapy as non satisfactory. The published trials on innovator etanercept show that ACR 20 response rate was not achieved in about 35 to $40 \%$ of patients till 6 months. ${ }^{13}$ The overall experience was rated as good, very good or excellent by $54.3 \%$ by patients and as OK by $22.9 \%$ of patients. Considering the fact that most of these patients had failed to respond to DMARDS, the response to Intacept looks good. While in study by Ashok Kumar and et al among 27 patients completing 104 weeks, secondary end points: ASAS 20, 40, and ASAS-partial remission status were achieved by $89 \%, 67 \%$, and $41 \%$, respectively.

In present study group , $4.29 \%$ develop injection site pain followed by fever in $2.86 \%$ of patients . While in study by Ashok Kumar et al injection site reactions were noted (exact percentage not specified) which was followed by upper respiratory tract infection as common side effects which was not noted in our study group. ${ }^{12}$ None of studied patients developed tuberculosis as compared to other study in which one patient developed tuberculous pleural effusion. Injection site reaction, pain and fever reported in this study are well established side effects of Etanercept. Some spontaneous reports of weight gain have also been seen with the innovator Etanercept. ${ }^{9}$ No new safety concerns were observed in the study.

When reason for dropout is analyzed, most important cause was non-response or inadequate response which is quite expected. Another important reason was affordability issue seen with $5.7 \%$ of population. Moreover, this affordability issue was despite the low price of Intacept compared to Innovator.

One of the important limitations of the study was that no specific established clinical evaluation parameter like ACR response or DAS was done. The only effectiveness criterion was the patient perceived effectiveness. Still, as the patient's experience is a good indicator of treatment response, the study data will definitely be important in adding to the present understanding of biosimilars presently being used in India. Other Limitations of this study is absence of control group to compare the results and limited number of study population. Despite these limitations, overall data show encouraging results on efficacy and safety of both the biosimilars.

\section{CONCLUSION}

The study leads to the conclusion that biosimilar etanercept (Intacept) was effective and safe in various rheumatic disorders. More observational and comparative studies are needed to further strengthen the case of biosimilars. In the modern era of biologicals, biosimilars have a huge potential to treat rheumatic disorders in India where affordability is a real challenge.

\section{ACKNOWLEDGEMENTS}

Authors would like to thank Dr. Niraj Jain, Dr. Alok Pandey, for his support during study.

\section{Funding: No funding sources \\ Conflict of interest: None declared \\ Ethical approval: Not required}

\section{REFERENCES}

1. Culy CR, Keating GM. Etanercept: an updated review of its use in rheumatoid arthritis, psoriatic arthritis and juvenile rheumatoid arthritis. Drugs. 2002;62(17):2493-537.

2. Eker DM, Jones SD, Levine HL. The therapeutic monoclonal antibody market. MAbs. 2015;7(1):9-14.

3. Kaida-Yip F, Deshpande K, Saran T et al Biosimilars: Review of current applications, obstacles, and their future in medicine. World $\mathrm{J}$ Clin Cases. 2018;6(8):161-6. 
4. Monti S, Todoerti M, Codullo V, Favalli EG, Biggioggero M, Becciolini A, et al. Prevalence of Ankylosing Spondylitis Disease Activity Score (ASDAS) inactive disease in a cohort of patients treated with TNF-alpha inhibitors. Modern Rheumatol. 2018;28(3):542-9.

5. Sengul I, Akcay-Yalbuzdag S, Ince B, GokselKaratepe A, Kaya T. Comparison of the DAS 28-CRP and DAS 28-ESR in patients with rheumatoid arthritis. Int J Rheumatic Dis. 2015 Jul;18(6):640-5.

6. Kvien TK, Uhlig T, ØdegÅrd S, Heiberg MS. Epidemiological aspects of rheumatoid arthritis. Annals of the New York academy of Sciences. 2006;1069(1):212-22.

7. Dean LE, Jones GT, MacDonald AG, Downham C, Sturrock RD, Macfarlane GJ. Global prevalence of ankylosing spondylitis. Rheumatol. 2014;53(4):650-7.

8. Yoo DH. The rise of biosimilars: potential benefits and drawbacks in rheumatoid arthritis. Expert Rev Clin Immunol. 2014;10:981-3.

9. Hlavatý T, Krajcovicova A, Šturdík I, Letkovský J, Koller T, Tóth J, et al. Biosimilar infliximab CT-P13 treatment in patients with inflammatory bowel diseases: a one-year, single-center retrospective study. Gastroenterologie a hepatologie. 2016;70(1):27-36.
10. Schmitz EM, Boekema PJ, Straathof JW, van Renswouw DC, Brunsveld L, Scharnhorst V, et al. Switching from infliximab innovator to biosimilar in patients with inflammatory bowel disease: a 12-month multicentre observational prospective cohort study. Alimentary Pharmacol Therapeut. 2018;47(3):356-63.

11. Ebbers HC, Muenzberg M, Schellekens H. The safety of switching between therapeutic proteins. Expert Opinion Biol Therapy. 2012 Nov 1;12(11):1473-85.

12. Kumar A, Goel A, Lapsiwala M, Goyal M, Dembla G. Clinical experience with two etanercept biosimilars in Indian patients with spondyloarthritis. Indian $\mathbf{J}$ Rheumatol. 2017;12(3):139-45.

13. ENBREL ${ }^{\circledR}$ (etanercept). Prescribing Information. Available at: http://www.accessdata.fda.gov/drugsatfda_docs/label /2003/etanimm060503LB.pdf. accessed on 29 Dec 2016

Cite this article as: Rath PD, Pandey SC. Biosimilar etanercept: a real world safety and patient related outcomes from a single centre. Int J Basic Clin Pharmacol 2019;8:892-6. 